\title{
Effect of retrogression and re-ageing heat treatment on microstructure and microhardness of aluminium 7010 alloy
}

\author{
Nandana M. S. ${ }^{1}$, Udaya Bhat $K .^{1 *}$ and C. M. Manjunatha ${ }^{2}$ \\ ${ }^{1}$ Department of Metallurgical and Materials Engineering, National Institute of Technology \\ Karnataka, India \\ ${ }^{2}$ Structural Technologies Division, CSIR-National Aerospace Laboratories, Bangalore, India
}

\begin{abstract}
Aluminium alloy 7010 is subjected to retrogression and reageing (RRA) heat treatment to study the influence of microstructural changes on hardness. Retrogression is performed at $190{ }^{\circ} \mathrm{C}$ for different time intervals ranging from 10 to 60 minutes. Optimum time for retrogression treatment is estimated based on the retrogression time that result with equivalent mechanical properties as that of peak aged (T6) condition. Retrogression performed for 30 minutes resulted with micro hardness of $203 \mathrm{HV}$, which is equivalent to that obtained by following T6 treatment. Microstructural characterization done with the help of transmission electron microscope (TEM) indicates RRA treatment results with the coarsened and discontinuous precipitates along the grain boundary which is similar to over aged (T7) condition, where as fine and densely populated precipitates in the matrix similar to T6 condition. Coarse and discontinuous grain boundary precipitates (GBP's) improves resistance to stress corrosion cracking. Fine and dense precipitates in the matrix ensures hardness equivalent to that of $\mathrm{T} 6$.
\end{abstract}

Keywords: RRA; Peak ageing; TEM; SCC; Microhardness

\section{Introduction}

Aluminium 7xxx series alloys is one of the high strength aluminium alloys used in aerospace structural applications mainly due to their high specific strength, damage tolerance and corrosion resistance properties [1]. They have $\mathrm{Zn}, \mathrm{Mg}$ and $\mathrm{Cu}$ as alloying elements, these alloys are precipitation hardened alloys, with general precipitation sequence in the order of supersaturated solid solution (SSSS) $\rightarrow$ GP zones $\longrightarrow \eta \dot{\eta} \rightarrow \eta\left(\mathrm{MgZn}_{2}\right)$ [2]. The $\eta$ precipitates formed during the precipitation sequence is the metastable precipitate of $\mathrm{MgZn}_{2}$, which is semicoherent with the matrix and is the major strengthening phase of the alloy. These alloys were earlier used in peak ageing (T6) condition, but during service, they are prone to stress corrosion cracking (SCC) due to the microstructural features like GBP's and coarse intermetallic particles [3]. Hence they are generally used in T7 condition which improves resistance to SCC. But the alloy during over ageing, looses its peak strength by about 10-15\% [4]. A three step heat treatment called retrogression and re-ageing is found out. It imparts the alloy with the strength characteristics of the T6 treated condition and SCC resistance of T7 treated condition [5].

\footnotetext{
* Corresponding author: udayabhatk@gmail.com
} 
A substantial amount of research work has been put forward in developing a mechanism for improving the stress corrosion properties of 7xxx series alloys. The improvement in the SCC is related to the grain boundary characteristics of the alloys. The increase in the size of the GBP's during coarsening stage and more spacing of them are responsible for the improved SCC resistance [6,7]. The mechanism of SCC is related to the formation of corrosion pits near the grain boundary segregations. In the presence of stress, these corrosion pits act as stress raisers leading to intergranular cracking [8].

The high strength aluminium alloys are used as structural materials in aircrafts, such as bulk heads and lug joints [9]. Since aircrafts are frequently exposed to saline environment during service, the alloys used in T6 treated condition, are more prone to SCC. The alloys heat treated to RRA condition are more resistant towards SCC, retaining the strength of T6 alloy. RRA studies on AA7010 with retrogression temperature in the range of $180-230^{\circ} \mathrm{C}$ has been reported [6]. But microstructure - mechanical property correlation for the RRA treated alloy is less studied. The aim of the present research work is to optimize the time of retrogression at $190{ }^{\circ} \mathrm{C}$ so as to obtain equivalent hardness as that of $\mathrm{T} 6$ treated sample and to study the microstructural changes during RRA.

\section{Experimental Procedures}

Material used for the current study is a high strength aluminium alloy, 7010 received in T7451 (over aged) condition. The alloy is composed of alloying elements Zn$6.3 \mathrm{Mg} 2.21 \mathrm{Cu} 1.65 \mathrm{Zr} 0.124 \mathrm{Fe}-0.21 \mathrm{Si}-0.073$ and rest is aluminium (wt \%). The alloy is subjected to solutionizing at $490{ }^{\circ} \mathrm{C}$ for $6 \mathrm{~h}$ and quenched in water, subsequently aged at different tempering conditions. The alloy is peak aged by heat treating at $120^{\circ} \mathrm{C}$ for $24 \mathrm{~h}$. Retrogression is performed by re heating the peak aged sample at $190{ }^{\circ} \mathrm{C}$ for different time intervals from $10-60 \mathrm{~min}$. The alloy is further re aged at $120{ }^{\circ} \mathrm{C}$ for $24 \mathrm{~h}$. Optimized temperature of reversion is evaluated based on the equivalent hardness of RRA sample as that of $\mathrm{T} 6$ treated sample. The tempering conditions adopted during the heat treatment are listed in Table 1. Heat treatment of alloy is successfully performed in a salt bath furnace.

Mechanical characterization of the heat treated alloy samples are done by performing the microhardness tests using Vicker's microhardness instrument (make Shimadzu, model: G21). The indentation load is 500 gms and time of indentation maintained for 15 secs. Microstructural characterization of the heat treated samples is done with the help of transmission electron microscope (TEM make JEOL, model: JEM 2100) operating at 200 $\mathrm{kV}$.

Table 1. Temper notations and corresponding heat treatment conditions

\begin{tabular}{|c|c|c|}
\hline Temper notations & Solutionization & $\begin{array}{c}\text { Ageing treatment (error } \pm \mathbf{2} \\
\left.{ }^{\circ} \mathbf{C}\right)\end{array}$ \\
\hline T6 (Peak ageing) & $490{ }^{\circ} \mathrm{C}-6 \mathrm{~h}$ & $120{ }^{\circ} \mathrm{C}-24 \mathrm{~h}$ \\
\hline $\begin{array}{c}\text { RRA (Retrogression } \\
\text { and re-ageing }\end{array}$ & $\begin{array}{c}490{ }^{\circ} \mathrm{C}-6 \mathrm{~h}+120^{\circ} \mathrm{C}-24 \mathrm{~h} \\
+ \text { Retrogression at } 190{ }^{\circ} \mathrm{C}\end{array}$ & Re-ageing at $120^{\circ} \mathrm{C}-24 \mathrm{~h}$ \\
\hline
\end{tabular}




\section{Results and Discussion}

The microstructure of the alloy sample in as received (T7451) condition is represented in Fig.1. The microstructure observed under light microscope reveals the grains oriented along the rolling direction with the average grain size of $12 \mu \mathrm{m}$. The evolution of hardening precipitates inside the matrix and along the grain boundaries is clearly evident from figure 1.

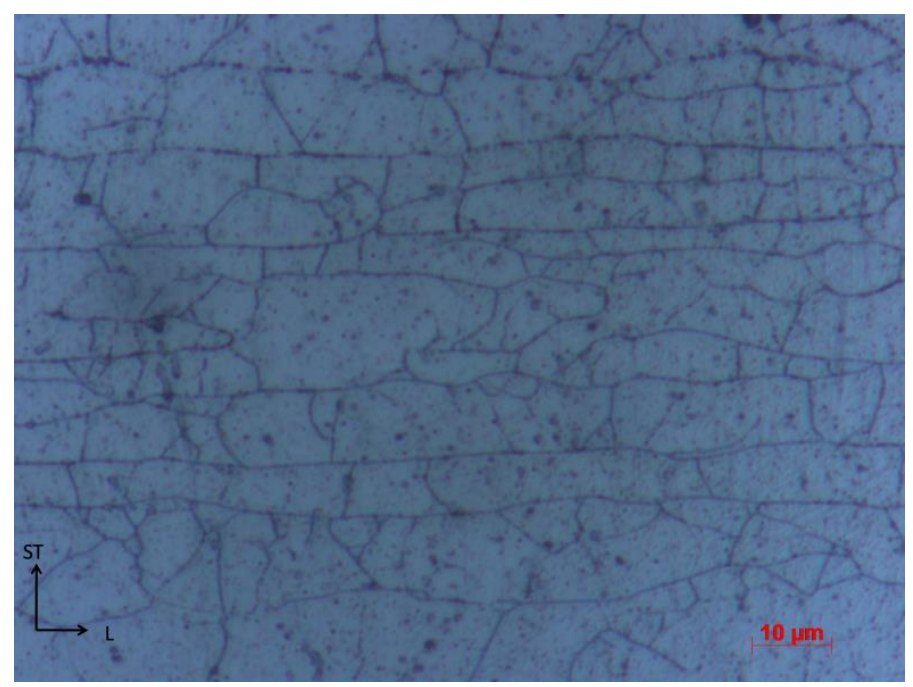

Fig. 1. Microstructure of AA7010 in T7451 (as received), etched with Kellers's reagent

The bright field TEM images corresponding to the matrix and the grain boundaries of T6 treated alloy is shown in Fig. 2. The matrix of the T6 treated sample is highly occupied with GP zones and fine scale metastable precipitates $\eta$ of size 3-5 nm. The GP zones are the clusters of solute atoms which are coherent with the matrix and $\dot{\eta}$ are the major strengthening phase of the high strength aluminium alloys, which are semicoherent with the matrix [10]. The grain boundary is occupied with continuous precipitates. The PFZ (precipitate free zone) size of T6 treated sample is in the range of 25-30 nm. 


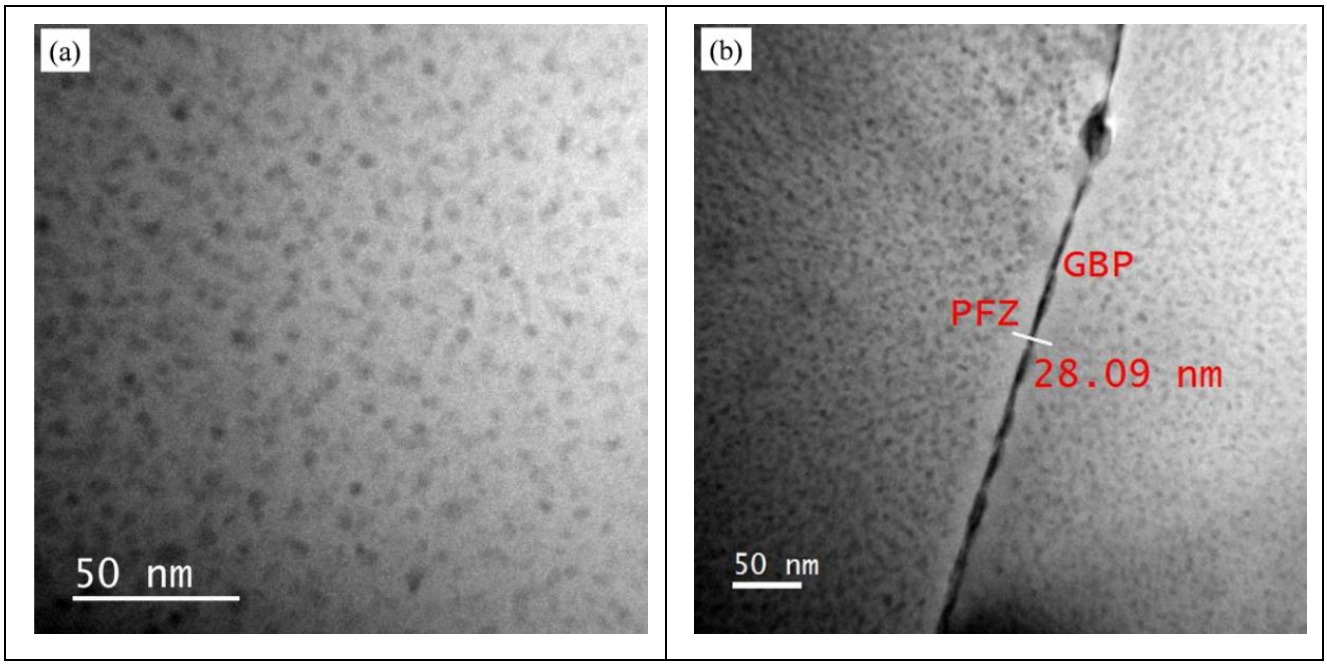

Fig. 2 TEM bright field micrographs of AA7010 in T6 condition: (a) matrix, (b) grain boundary

The microhardness of the T6 treated sample is $196 \mathrm{HV}$, represented by straight line in Fig. 3. Retrogression is performed at a temperature higher than the peak ageing temperature, at $190{ }^{\circ} \mathrm{C}$, during which the GP zones gets completely dissolved in the matrix and fine scale $\eta$ precipitates are partially dissolved. This is evident from the valley in the hardness plot $[11,6]$. With the increase in the retrogression time, the hardness gets increased up to a limit from where coarsening and transformation of $\eta$ into stable $\eta$ precipitates takes place $[12,13]$. It is evident from the development of secondary peak as noticed in the hardness plot in Fig. 3. Upon re-ageing the retrogressed sample, the dissolved solutes will re precipitate and grow. Presence of re nucleated fine scale precipitates in addition to the partially dissolved precipitates that remained during retrogression makes the matrix denser compared to the matrix of T6 treated sample as observed in Fig. 4(a).

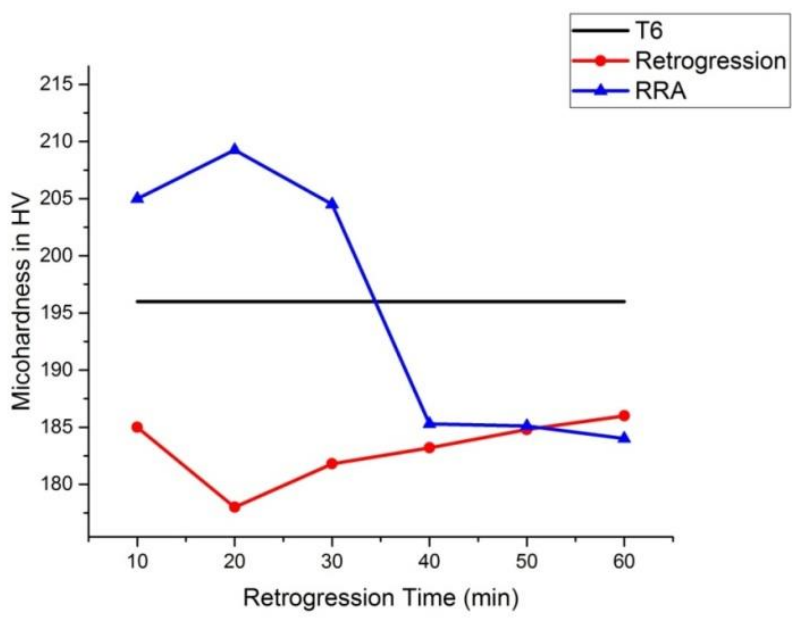

Fig. 3 Plot of microhardness vs retrogression time for AA7010 under different temper conditions. 
The size of the matrix precipitates vary from 5-8 nm in RRA treated sample. During reageing, the existing continuous GBP's gets coarsened and get arranged in a discontinuous fashion [Fig. 4(b)]. The size of GBP's varies from 30-40 nm and PFZ size varies from 40$60 \mathrm{~nm}$. Whereas, in T7451 (as received) condition the matrix is partly occupied with fine precipitates of size 7-10 nm and partly occupied with large and coarsened precipitates of $16-40 \mathrm{~nm}$ in size [Fig. 4(c,d)]. This observation is similar to the reported literature [14]. The coarsened precipitates are responsible for lowering the strength in over aged alloys. Apart from coarsening of GBP's the electrochemical potential of the GBP's gets increased by diffusion of more $\mathrm{Cu}$ into them, thereby delaying the formation of corrosion pits. This is expected to increase the resistance the alloy towards SCC $[15,16]$.

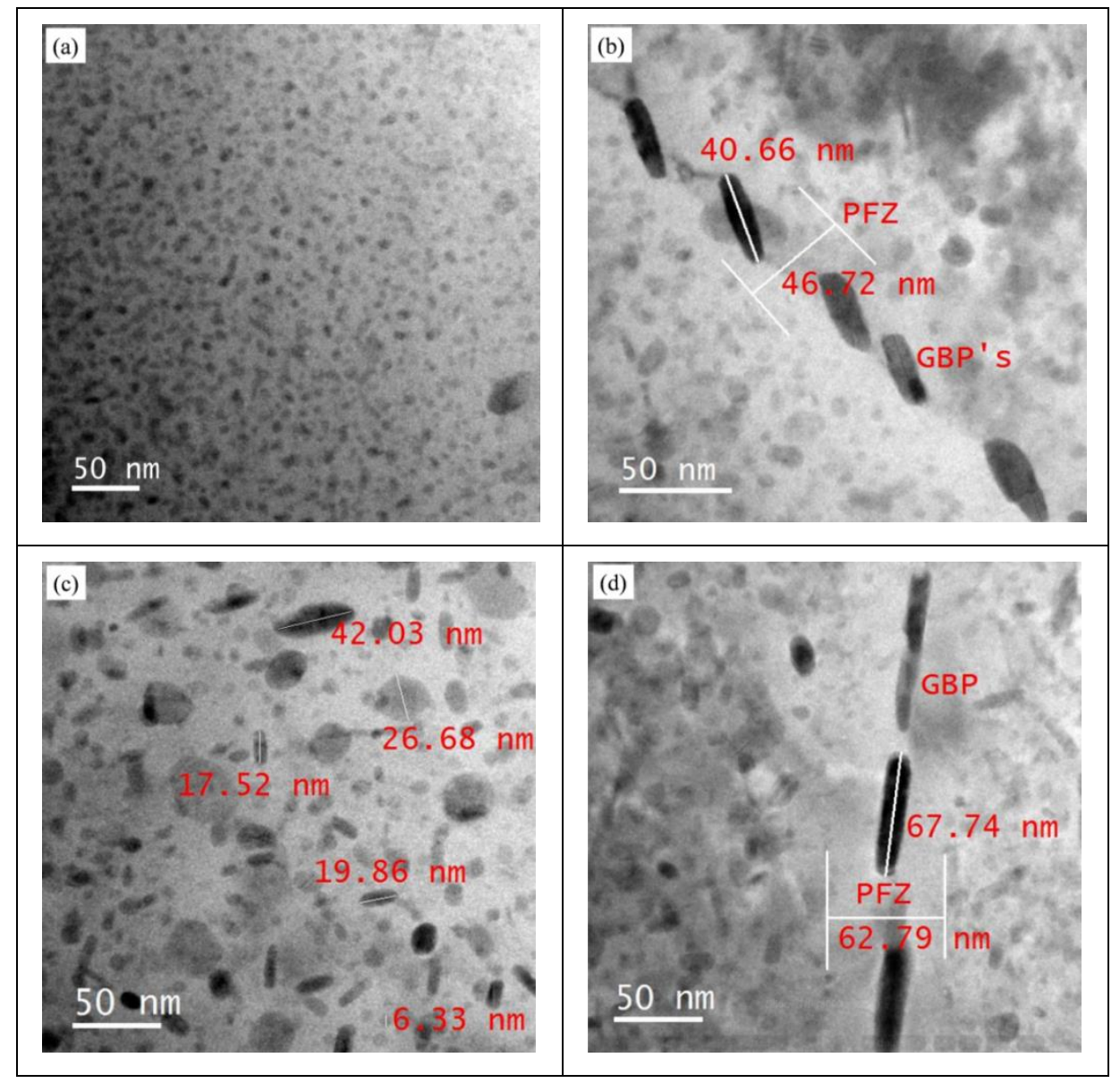

Fig. 4 TEM bright field micrographs of AA7010: (a,b) RRA (retrogressed at $190{ }^{\circ} \mathrm{C}$ for $\left.30 \mathrm{~min}\right),(\mathrm{c}, \mathrm{d})$ T7451 (as received) 


\section{Conclusions}

1. The matrix of the RRA treated sample is more densely occupied with strengthening precipitates ( $\eta$ ) compared to T6 treated sample, hence hardness of the RRA treated samples is much higher than the standard peak aged sample.

2. The grain boundary precipitates of RRA treated sample is coarsened similar to that of the over aged sample which will influence in imparting better corrosion resistance to the alloy.

3. The isolated GBP's will enhance the resistance to crack propagation during SCC.

\section{Acknowledgements}

Authors are thankful to The Director, CSIR-NAL for facilitating to conduct this research work. One of the authors Mr. Nandana thanks the Director, NITK for the fellowship grant.

\section{References}

1. J. C. Williams, E. A. Starke, Acta Mater, 51, 5775-5799 (2003)

2. G. Peng, K. Chen, S. Chen, H. Fang, Mater. Sci. Eng. A, 528, 4014-4018 (2011).

3. M. B. Kannan, V. S. Raja, J mater Sci, 42, 5458-5464 (2007).

4. M. Dixit, R. S. Mishra, K. K. Sankaran, Mater. Sci. Eng. A, 478, 163-172 (2008).

5. C. Bora, US3856584 A, (1974)

6. F. Viana, A. M. P. Pinto, H. M. C. Santos, A. B. Lopes, J. Mater. Process. Technol, 92-93, 54-59 (1999)

7. Y. P. Xiao, Q. L. Pan, W. B. Li, X. Y. Liu, Y. B He, Mater. Des, 32, 2149-2156 (2011)

8. J. S. Robinson, Mater. Sci. Eng. Tech, 390, 385-390 (2003)

9. J. Schijve, Int. J. Fatigue, 31, 998-1011 (2009)

10. J. Buha, R. N. Lumley, A. G. Crosky, Mater. Sci. Eng. A, 492, 1-10 (2008).

11. M. Kanno, I. Araki, Mater. Sci. Technol, 10, 599-603 (1994).

12. N. C. Danh, K. Rajan, W. Wallace, Metall. Trans, 14, 1843 (1983)

13. T. Marlaud, A. Deschamps, F. Bley, W. Lefebvre, B. Baroux, Acta Mater, 58, 4814$4826(2010)$

14. P. Kumar Rout, M. Ghosh, K. Ghosh, Procedia Mater. Sci, 5, 1214-1223 (2014).

15. M. Angappan, V. Sampath, B. Ashok, V. P. Deepkumar, Mater. Des, 32, 4050-4053 (2011).

16. T. Marlaud, A. Deschamps, F. Bley, W. Lefebvre, B. Baroux, Acta Mater, 58, 248-260 (2010). 